\title{
PENGARUH KETIDAKPASTIAN LINGKUNGAN TERHADAP KINERJA BISNIS DENGAN STRATEGIC FLEXIBILITY SEBAGAI VARIABEL MEDIASI
}

\author{
Nurbaity Fahmia ${ }^{1^{*}}$ \\ ${ }^{1}$ Magister Manajemen, Universitas Brawijaya Malang \\ *fahmia.nurbaity@gmail.com
}

\begin{abstract}
:
This purpose of this research is to identify and analyze the affect of environmental uncertainty on business performance, the affect of environmental uncertainty on strategic flexibility, and the affect of strategic flexibility to business performance. Strategic flexibility as a mediation variable. The design of this research is explanatory research. The research object are the Small Real Estate Developers (REDs) in the region of Probolinggo. The analysis uses is Partial Least Square (PLS).

The results shows that there are influence between environmental uncertainty on business performance, environmental uncertainty on strategic flexibility, strategic flexibility to business performance, and strategic flexibility mediate environmental uncertainty on business performance. Nevertheless the mediating role of strategic flexibility in determining the magnitude of the influence of environmental uncertainty on business performance is smaller than the direct affect. Overall the results of this study indicate that if the uncertainty of the environment as a combination of the state uncertainty, the effect uncertainty and the response uncertainty can be used as a basis for Small Real Estate Developers (REDs) in forming strategic flexibility, then Small Real Estate Developers (REDs) will be able to improve its business performance
\end{abstract}

Keywords: Environmental uncertainty, strategic flexibility, business performance, Small Real Estate Developers (REDs)

\section{PENDAHULUAN}

Seiring dengan berkembangnya UKM developer di berbagai daerah dan perannya dalam turut menopang perekonomian Indonesia, UKM developer juga dihadapkan pada ketidakpastian lingkungan yang tinggi. Sifatnya yang informal di satu sisi membuat mereka sulit bertahan, namun di sisi lain strategic flexibility menjadi salah satu potensi yang patut dikembangkan.

Penelitian yang dilakukan oleh Isabela dan Waddock (1994) menemukan hubungan positif antara kinerja organisasi terhadap ketidakpastian lingkungan, penelitian ini mendasari Bastian dan
Muchlish (2012) dengan argumen yaitu adanya hubungan positif antara persepsi ketidakpastian lingkungan dan kinerja organisasi. Pada penelitian Bastian dan Muchlish (2012) yang tercantum pada hipotesa ketiga menyebutkan bahwa ketidakpastian lingkungan hanya mempengaruhi kinerja organisasi pada kinerja lini non-keuangan, sedangkan untuk kinerja keuangan tidak terpengaruhi.

Hasil riset yang lain menunjukan bahwa perusahaan yang memiliki kemampuan dalam menerapkan strategic flexibility akan lebih memiliki kinerja yang lebih baik dibandingkan dengan perusahaan 
yang tidak menerapkan strategic flexibility. Hal ini seperti yang diungkapkan dalam penelitian oleh Herman dkk tahun 2008 pada Isuzu di salah satu pulau di Indonesia yaitu terjadinya strategic flexibility di dalam perusahaan didorong oleh adanya ketidakpastian lingkungan.Yaitu adanya kebijakan pemerintah melalui SK Menterian Lingkungan Hidup No.141 mengenai dampak emisi gas buang kendaraan. Kondisi ini yang mendorong industri otomotif untuk menerapkan strategic flexibility dengan melakukan perubahan strategi dan inovasi teknologi. Seperti perubahan pada komponen produk, perubahan spesifikasi kendaraan dan pada akhirnya akan terjadinya perubahan pada strategi marketing. Untuk mendukung strategi tersebut, secara internal perusahaan perlu melakukan pemetaan kebijakan untuk mengontrol organisasi. Seperti mulai menganalisa dampak emisi terhadap lingkungan yang ditindaklanjuti dengan penerapan teknologi baru, perubahan pola perilaku. Sedangkan secara eksternal, perusahaan perlu memperhatikan dari segi pelanggan dan pesaing. Untuk pesaing termasuk di tingkat manakah Isuzu bersaing, apakah persaingan ketat, sedang atau rendah, sedangkan untuk pelanggan bagaimana respon mereka terhadap adanya kebijakan Euro 2 dan sebagainya. Sedangkan pengukuran strategic flexibility dari perusahaan, pengukuran dilakukan dengan depth interview dengan para top management perusahaan baik dari segi Research and Development, Financial, Marketing, Operating, International, dan Managerial \&Structural. Dengan adanya pengukuran variable-variabel dan analisa, maka pada akhirnya dihasilkan suatu New Product Development yang sesuai dengan keinginan dan kemauan dari pasar.

Pendekatan yang digunakan dalam menganalis faktor-faktor yang diinginkan konsumen terhadap pengembangan produk. Hal ini berdasarkan pendapat R Lauterborn sebagaimana dikutip oleh Kottler dan Susanto (2000) bahwa secara keseluruhan konsumen Isuzu menganggap faktor customer needs, wants dan demand sangat penting. Isuzu merespon positif terhadap regulasi pemerintah mengenai standar Euro 2 dengan tetap memperhatikan preferensi pasar terhadap produk yang diinginkan konsumen. Untuk menghadapi persaingan industri setelah dikeluarkannya regulasi pemerintah mengenai standar Euro 2. Isuzu telah mengambil langkah strategis dengan memproduksi produk yang sesuai standar Euro 2. Strategic flexibility yang dilakukan adalah dengan melakukan modifikasi produk melalui penambahan fasilitas (supporting parts) berupa catalytic converter dan head piston guna mereduksi emisi gas buang kendaraan sesuai dengan standar Euro 2 dan sesuai dengan preferensi pasar. Hasil kinerja yang tercapai yaitu Isuzu tetap menjadi market leader kendaraan mesin diesel.

Dalam penelitian Perez et al., 2014 menunjukkan bahwa CEO akan lebih insentif untuk mengembangkan Strategic Flexibility ketika ada suatu iklim ketidakpastian lingkungan yang tinggi.Argumen ini mendukung teori strategic flexibility yang dapat didefinisikan sebagai kemampuan organisasi untuk mengidentifikasi besar perubahan dalam lingkungan eksternal dengan mendayagunakan sumber daya yang ada menanggapi perubahan,dan untuk mengenali serta bertindak segera ketika saatnya untuk berhenti(Shimizu dan Hitt, 2004; 45).

Disisi lain dikemukakan oleh Arnold et al., 2015 dinyatakan bahwa lingkungan eksternal yang dinamis menyebabkan pengambil keputusan mengambil langkah strategic flexibility ternyata memiliki hubungan yang positif dengan kinerja perusahaan. Pengujiannya dengan menggunakan data dari kepala audit eksekutif yang memberikan dukungan yang kuat untuk teori. Hasil penelitian menunjukkan bahwa para pengambil keputusan dalam rangka meningkatkan ERM mereka meningkatkan fleksibilitas dan berdampak positif pada kinerja.

Praktik strategic flexibility juga dilakukan pada perusahaan China melalui Green Management dalam penelitian yang dilakukan oleh J Yang (2015) memberikan 
implikasi pentinguntuk menjelaskan bagaimana perusahaan di negara berkembang menggabungkan strategic flexibility internal dan eksternal berupa dukungan kelembagaan untuk menerapkan Green Management, yang pada gilirannya meningkatkan legitimasi mereka dandaya saing. Green Management saat ini dipandang sebagai strategi lingkungan proaktif (Molina et al., 2009).

Ketika perusahaan mengadopsi Green Management hal ini mengacu pada keputusan perusahaan dalam menanggapi isu-isu lingkungan dan sosial (Lin dan Ho, 2011).Namun ada beberapa kendala diantaranya tantangan defisit sumberdaya. Untuk mengatasi tantangan defisit sumber daya dan mengatasi keterbatasan kemampuan perusahaan dalam perusahaan harus mampu fleksibel mengalokasikan dan mengkoordinasikan sumber daya mereka secara efektif ketika mengadopsi Green Management (Xin dan Pearce, 1996).

Menurut perspektif kemampuan dinamis, strategic flexibility mencerminkan kemampuan perusahaan untuk mengalokasikan dan mengkonfigurasi ulang sumber dayanya, proses, dan strategi untuk menghadapi perubahan lingkungan(Zhou dan Wu, 2010: 549). Strategic flexibility memungkinkan perusahaan secara cepat dan efektif mengkonfigurasi ulang dan berinvestasi sumber daya dan kemampuan untuk menanggapi secara efektif untuk mengubah (Bock et al, 2012; Sanchez, 1997). Strategic flexibility memungkinkan perusahaan untuk beradaptasi dalam pengelolaan sumber daya mereka untukberbagai kegunaan dalam efektif menyebarkan green design, green manufactur dan green marketing. Perusahaan yang sangat fleksibel pada akhirnya mampu mengkoordinasikan penggunaan sumber daya mereka dengan mendefinisikan kembali strategi mereka, konfigurasi ulang rantai pasokan mereka, dan re-deployingsumber daya mereka secara efektif (Sanchez, 1997; Zhou dan Wu, 2010).

Berbeda lagi dengan hasil penelitian yang disampaikan oleh Yuan $\mathrm{Li}$ dan Zhongfeng Su tahun 2011 yang mengadopsi teori perubahan lingkungan.Sebagai kunci perubahan lingkungan, perubahan strategis pada lingkungan ditekankan sebagai faktor utama terhadap kelangsungan hidup dan keberhasilan perusahaan-perusahaan yang mengalami ketidakpastian lingkungan secara signifikan (Boeker, 1989; Webb dan Dawson, 1991). Namun bisa jadi hanya dengan mengubah strategi mungkin tidak mencukupi untuk menjamin keberhasilan suatu perusahaan (Kelly dan Amburgey, 1991; Zajac dan Shortell, 1989).

Ketika perusahaan mendapati bahwa lingkungan mereka menjadi sangat tidak pasti, mereka harus merespon dengan cepat menghadapi tantangan dari perubahan lingkungan (Tushman dan O'Reilly, 1996). Eisenhardt (1989) menunjukkan bahwa perubahan dalam ketidakpastian lingkungan yang tinggi yaitu semakin besar kecepatan perubahan strategis maka semakin baik pula kinerja perusahaan. Meskipun Strategic Flexibility memungkinkan perusahaan untuk menghadapi perubahan lingkungan danmencapai keunggulan kompetitif di pasar bergolak (Eisenhardt dan Martin, 2000), namun ada perbedaan hasil dari implementasi fungsi Strategic Flexibility.

Diungkapkan bahwa pengaruh strategic flexibility yang terdiri dari resource flexibility dan coordination flexibility menghasilkan ketimpangan hasil. Hal ini dikarenakan perekonomian China berbeda dibandingkan negara berkembang lainnya. Beberapa studi empirik sebagaimana dikemukakan diatas menyajikan hasil yang berbeda-beda mengenai komponenkomponen utama yang mempengaruhi kinerja bisnis.

Bastian dan Muchlish (2012) mengemukakan bahwa hasil dari penelitian di perusahaan manufaktur sebanyak 86 responden terdapat pengaruh yang signifikan antara ketidakpastian lingkungan terhadap kinerja bisnis. Hal ini juga sejalan dengan penelitian yang dilakukan oleh Purnomo dan Subroto (2016) hasil dari penelitian 150 UKM adalah terdapat pengaruh yang signifikan antara ketidakpastian lingkungan terhadap kinerja bisnis serta hasil yang lain 
yaitu tidak ada hubungan antara dimensi intensitas persaingan terhadap kinerja bisnis. Akan tetapi hasil penelitian oleh Timilsina (2016) ketidakpastian lingkungan yang turbulen memiliki dampak negatif pada kinerja bisnis dalam dimensi kinerja keuangan dan operasional.

Berdasarkan temuan dari penelitianpenelitian tersebut dapat dikemukakan bahwa ketidakpastian lingkungan memiliki korelasi yang erat dengan kinerja bisnis. Oleh karena itu perlu dilakukan pengujian lebih lanjut apakah ketidakpastian memiliki pengaruh terhadap kinerja bisnis, dengan merumuskan hipotesis sebagai berikut :

$H_{1}$ : Ketidakpastian lingkungan akan mampu meningkatkan kinerja bisnis

Perusahaan dalam operasinya dipengaruhi oleh lingkungan, baik secara langsung maupun tidak langsung. Pearce dan Robbinson (2003) mengemukakan bahwa, kondisi lingkungan secara langsung mempengaruhi kemampuan perusahaan untuk mencapai tujuan. Di bawah kondisi tekanan lingkungan yang tidak pasti, perencanaan strategis dapat menjadi berubah dan dapat menjadi se-fleksibel mungkin.Perusahaan harus dapat mengatasi dan menyesuaikan terhadap perubahan kondisi yang tidak pasti dan lingkungan yang turbulen (Hopkins dan Shirley, 1997). Ini meyakini pandangan bahwa untuk merespon ketidakpastian dengan menyesuaikan objektif yang ada dengan didukung oleh kemampuan dan pengetahuan yang superior (Lau, 1996) dengan pengurangan ketidakpastian melalui strategic flexibility dengan baik tinggi sebagai satu cara agar tujuan perencanaan strategis bisa berhasil kemampuan perusahaan. Sementara menurut Patel (2012) strategic flexibility umumnya dianggap perlu bagi organisasi untuk mengelola kecepatan perubahan lingkungan yang tidak pasti dan meningkatkan kinerja organiasi yaitu yang dibahas pada penelitian tersebut adalah kinerja supply chain. Namun hal ini tidak sejalan dengan hasil penelitian Combe et al. (2012) yang menegaskan bahwa ketidakpastian lingkungan tidak berpengaruh secara signifikan terhadap penerapan strategic flexibility dan ternyata diperlukan strategic options yang lain. Combe et al. (2012) menyarankan penelitian di masa depan sebaiknya menguji dan membuka gap diantara ketidakpastian lingkungan dan strategic flexibility pada perusahaan secara empiris. Berdasarkan temuan dari penelitianpenelitian tersebut dapat dikemukakan bahwa ketidakpastian lingkungan memiliki korelasi yang erat dengan strategic flexibility. Oleh karena itu perlu dilakukan pengujian lebih lanjut apakah ketidakpastian memiliki pengaruh terhadap strategic flexibility, dengan merumuskan hipotesis sebagai berikut :

$\mathrm{H}_{2}$ : Ketidakpastian lingkungan akan mampu meningkatkan strategic flexibility.

Menurut Shimizu (2004), strategic flexibility amat erat hubungannya dengan kapabilitas dinamis, karena sebagian dari proses kapabilitas dinamis dalam mengeksekusi keputusan-keputusan bisnis dapat ditafsirkan sebagai strategic flexibility.

Penelitian yang dilakukan oleh Herman et al. (2008) mengungkapkan bahwa penerapan strategic flexibility mempengaruhi kinerja bisnis secara signifikan dan sebagai tambahan pada akhirnya perusahaan mengalami survive and compete in market. Perez et al. (2014) meneliti tentang perilaku CEO untuk mencapai kinerja perusahaan mereka menerapkan strategic flexibility. Serta Yan (2015) mengemukakan bahwa strategic flexibility sebagai kemampuan dinamis yang pada akhirnya memiliki pengaruh positif terhadap kinerja bisnis dan diakui bahwa di negara-negara berkembang strategic flexibility perlu diterapkan. Argumentasi yang dikemukakan oleh Li (2011) bahwa perusahaan kecil didirikan sebagai organisasi yang fleksibel mencerminkan bahwa organisasi ini sangat potensial untuk menciptaan aktivitas secara fleksibel sehingga akan mendorong untuk menerapkan kebijakan strategi yang sesuai dengan dinamika lingkungan, namun strategic flexibility saja dirasa kurang. Perlu beberapa upaya (variabel moderasi) yang lain untuk mencapai kinerja bisnis. 
Berdasarkan temuan dari penelitianpenelitian tersebut dapat dikemukakan bahwa strategic flexibility memiliki korelasi yang erat dengan kinerja bisnis. Oleh karena itu perlu dilakukan pengujian lebih lanjut apakah strategic flexibility memiliki pengaruh terhadap kinerja bisnis, dengan merumuskan hipotesis sebagai berikut :

$\mathrm{H}_{3}$ : Strategic flexibility akan mampu meningkatkan kinerja bisnis

Hubungan antara ketidakpastian lingkungan terhadap kinerja bisnis telah banyak dieksplorasi di beberapa penelitian sebelumnya.Secara konseptual beberapa peneliti menunjukkan bahwa ketidakpastian lingkungan berhubungan dengan kinerja bisnis seperti Bastian dan Muchlish (2012), Timilsina (2016) dan Patel (2012). Sedangkan peneliti lain seperti Combe, et al., (2012) menemukan konsepsi hubungan tersebut. Selanjutnya beberapa peneliti yang lain beranggapan bahwa hubungan antara ketidakpastian lingkungan dan kinerja bisnis dapat bersifat tidak langsung, karena adanya kompleksitas yang ada pada hubungan tersebut. Oleh karena itu beberapa peneliti beranggapan bahwa hubungan antara ketidakpastian lingkungan dan kinerja bisnis harus dimediasi/dimoderasi oleh variabel lain.Dalam teknologi dan manajemen inovasi dalam literature teori organisasi, konsep strategic flexibility mengacu pada fleksibilitas manufaktur atau operasional dan umumnya terkait dengan penciptaan system manufaktur fleksibel dan administrasi (Gerwin, 1993; Upton, 1995).Meskipun demikian konsepsi strategic flexibility bersifat multidimensi (Hamel, et al., 1998) sehingga dapat diterapkan pada berbagai disipllin ilmu (Combe, 2012).Beberapa bentuk dari strategic flexibility berkaitan dengan konsep ketidakpastian lingkungan dan kinerja bisnis (Majid, 2013). Berdasarkan penjelasan tersebut maka hipotesa terakhir yang terbentuk adalah:

$\mathrm{H}_{4}$ : Strategic flexibility akan mampu memediasi hubungan antara ketidakpastian lingkungan dengan kinerja bisnis

\section{METODE}

Rancangan penelitian ini bersifat explanatory research. Unit analisis pada penelitian ini adalah perusahaan properti dengan sampel jenuh sebanyak 48 managerowner properti di wilayah Probolinggo. Penelitian ini dilakukan pada bulan Desember 2016, analisis yang digunakan adalah Partial Least Square (PLS).

Populasi dari penelitian ini yaitu seluruh developer pada level manager/owner/staff senior yang dianggap mampu mengambil keputusan di wilayah kabupaten dan kota Probolinggo sebanyak 50 orang. Developer skala kecil adalah usaha ekonomi produktif yang dilakukan orang perseorangan atau badan usaha yang bukan anak perusahaan atau cabang perusahaan yang dimiliki, dikuasai, atau menjadi bagian langsung maupun tidak langsung dengan memiliki kekayaan bersih lebih dari Rp. 500.000.000 (lima ratus juta rupiah) sampai dengan Rp. 10.000.000.000 (sepuluh milyar rupiah) tidak termasuk tanah dan tempat bangunan usaha atau hasil penjualan tahunan $>$ Rp. 2,5 milyar s.d. Rp. 50 milyar (UU No. 20 Tahun 2008 tentang Usaha Micro, Kecil dan Menengah, pasal 6 ayat 3). Sampel yang digunakan dalam penelitian ini didapat dengan teknik pengambilan sampel jenuh. Menurut Riduwan (2012) sampling jenuh merupakan teknik pengambilan sampel dimana semua populasi digunakan sebagai sampel dan dikenal dengan istilah sensus. Arikunto (2006) mengemukakan bahwa jika subjek penelitian kurang dari 100 orang maka sebaiknya diambil semua penelitian populasi.Pada penelitian dari 50 orang hanya 48 responden yang bersedia berpartisipasi maka peneliti menyesuaikan dengan kesediaan responden.

Menurut Sugiyono (2012: 31), definisi operasional adalah penentuan konstrak atau sifat yang akan dipelajari sehingga menjadi variabel yang dapat diukur. Definisi operasional menjelaskan cara tertentu yang digunakan untuk meneliti dan mengoperasikan konstrak, sehingga memungkinkan bagi peneliti yang lain untuk melakukan replikasi pengukuran dengan cara 
yang sama atau mengembangkan cara pengukuran konstrak yang lebih baik.

Ketidakpastian lingkungan adalah peristiwa yang tidak bisa dibayangkan tetapi bisa/mungkin terjadi di waktu depan (Miliken dan Fisher, 1987). Sesuai dengan batasan penelitian maka dalam penelitian ini diukur dengan tiga dimensi, yaitu : a. State Uncertainty yaitu jika seorang manajerowner merasa bahwa lingkungan organisasi tidak dapat diprediksi. Konstruk pembangun item dari dimensi state uncertainty adalah (1) Perubahan teknologi; (2) Taste and needs; (3) Perubahan tren ; (4) Kebijakan Perbankan ; (5) Peraturan Pemerintah; (6) Persaingan. b. Effect uncertainty yang mengacu pada ketidakmampuan manajer-owner untuk memprediksi pengaruh lingkungan terhadap organisasi yaitu pemahaman tentang hubungan sebab-akibat. Konstruk effect uncertainty dibentuk dari fenomena berdasarkan persepsi manajer-owner (Sund, 2015). Pengukuran indikator ini diperoleh dari wawancara pendahuluan didapatkan item yaitu (1) Budaya dengan item adanya perbedaan nilai terkait kredit di masyarakat yang berhubungan dengan sumber pendanaan utama developer, (2) Pesaing melakukan strategi dan bertindak di pasar dengan item dampak dari adanya perubahan strategi pesaing. c. Response uncertainty berkaitan dengan ketidakmampuan memprediksi konsekwensi dari pilihan-pilihan keputusan untuk merespon perubahan lingkungan yang terjadi. Maka dari proses pembentukan item melalui wawancara pendahuluan menghasilkan : (1) Respon masyarakat terhadap penawaran produk inovatif ; (2) Efektivitas langkah-langkah stratejik sulit diprediksi;

Strategic flexibility diartikan sebagai "kunci untuk tumbuh"(Hatch et al., 2001). Sebagai strategi perusahaan untuk tumbuh cepat merespon dan sukses beradaptasi dengan perubahan lingkungan (Greenlay, 2004). Sejauh mana pilihan dan alternatif baru dalam pengambilan keputusan yang dinilai layak oleh manajer-owner. Dalam penelitian ini variabel ini dikukur dengan tiga dimensi yaitu: a. Perhatian merupakan kemampuan dari perusahaan untuk menunjukkan kepekaan dari perubahan lingkungan dalam bentuk memberikan umpan balik (Shimizu dan Hitt, 2004). Dalam penelitian ini, perhatian dijelaskan sebagai kemampuan perusahaan dalam merespon perubahan lingkungan melalui pengambilan keputusan yang strategis.b. Assesment merupakan kemampuan perusahaan dalam memberikan penilaian terhadap faktor-faktor eksternal dan selanjutnya mereka dapat memberikan respon (Teece, et al., 1997 ; Shimizu dan Hitt, 2004). Dalam penelitian ini assessment dijelaskan sebagai kemampuan perusahaan dalam memberikan penilaian terhadap perubahan lingkungan melalui penilaian faktor eksternal.c.Tindakan merupakan kemampuan dari perusahaan untuk mengevaluasi dan memprediksi perubahan lingkungan yang dapat berdampak pada hasil yang dicapai (Shimizu dan Hitt, 2004). Dalam penelitian ini, tindakan dijelaskan sebagai kemampuan perusahaan dalam menciptakan posisi yang lebih baik dari tekanan persaingan.

Kinerja Bisnis, di dalam sistem kontrol formal ukuran kinerja meliputi ukuran financial dan non financial (Fisher, 1998) dalam (Astuti dan Sabeni,2005). Indikator kinerja bisnis yang baik dapat berupa meningkatnya produktivitas, pertumbuhan penjualan, peningkatan laba, unggul dalam persaingan. Hal yang menarik bahwa di beberapa penelitian terdahulu adalah bahwa banyak perusahaan kecil dan menengah masih menggunakan ukuran kinerja tradisional, yaitu dengan mengukur provitability (profitabilitas), pertumbuhan penjualan, efisiensi (Thomas, et al , 2008). Dalam penelitian ini kinerja keuangan diukur dari provitability, pertumbuhan penjualan dan efisiensi.

Survey yang dilakukan dengan menggunakan online / electronic questionnaire menggunakan aplikasi google form. Waktu pengisian online / electronic questionnaire diberikan tenggang waktu selama 14 hari. Penyebaran kuesioner dilakukan juga dengan cara membagikan 
langsung kepada para pengambil keputusan (manajer-owner).

Rancangan kuesioner dalam penelitian ini terdiri dari 2 bagian yaitu karakteristik responden dan data pengukuran variabel. Data responden terdiri dari nama, status, jenis kelamin, umur, tingkat pendidikan, lama bekerja. Responden terlebih dahulu diseleksi sebelum mengisi kuesioner agar mendapatkan responden yang sesuai dengan tujuan. Pada analisis statistik adalah kuesioner dengan menggunakan skala Likert 1-5 dimana 1 adalah "Sangat Tidak Setuju” dan 5 adalah "Sangat Setuju”. Untuk informasi pendukung menggunakan studi pustaka yaitu pengumpulan informasi dan data dengan bantuan berbagai macam material yang berasal dari literatur maupun dari karya ilmiah yang berhubungan dengan penelitian.Selain itu dibutuhkan informasi kualitatif. Informasi kualitatif yang digunakan dalam penelitian ini adalah wawancara mendalam (in depth interview). Informasi kualitatif ini digunakan untuk mendukung dan mengungkapkan fakta-fakta dibalik temuan analisis kuantitatif. Wawancara dilakukan lebih rinci kepada salah satu informan yang dianggap mampu memberikan informasi tentang segala sesuatu yang terkait dengan penelitian. Menurut Tailor dan Bogdan (1998) wawancara mendalam adalah pertemuan tatap muka dengan seorang informan yang dilakukan berulang-ulang yang bertujuan untuk memperoleh pemahaman mengenai perspektif informan mengenai suatu hal yang diungkapkan dalam kata-kata informan itu sendiri.

\section{HASIL}

Pengujian validitas instrumen dilakukan dengan cara mengkorelasikan setiap skor item dengan skor total menggunakan teknik Korelasi Pearson (Product Moment). Kriteria pengujian menyatakan apabila koefisien korelasi $\left(\mathrm{r}_{\mathrm{iT}}\right) \geq$ korelasi table $\left(\mathrm{r}_{\text {tabel }}\right)$ berarti item kuesioner dinyatakan valid atau mampu mengukur variabel yang diukurnya, sehingga dapat dipergunakan sebagai alat pengumpul data
Hair et al. (2013). Adapun ringkasan hasil pengujian validitas sebagaimana tabel 1

Tabel 1. Hasil Uji Validitas

\begin{tabular}{|c|c|c|c|c|c|}
\hline Variabel & Dimensi & Item & r hitung & $r$ tabel & Keterangan \\
\hline \multirow{10}{*}{$\begin{array}{l}\text { Ketidakpast } \\
\text { ian } \\
\text { Lingkungan }\end{array}$} & \multirow{6}{*}{ State uncertainty } & KLS1 & 0.681 & 0.361 & Valid \\
\hline & & KLS2 & 0.548 & 0.361 & Valid \\
\hline & & KLS3 & 0.794 & 0.361 & Valid \\
\hline & & KLS4 & 0.875 & 0.361 & Valid \\
\hline & & KLS5 & 0.810 & 0.361 & Valid \\
\hline & & KLS6 & 0.776 & 0.361 & Valid \\
\hline & \multirow{2}{*}{ Effect uncertainty } & KLE1 & 0.944 & 0.361 & Valid \\
\hline & & KLE2 & 0.930 & 0.361 & Valid \\
\hline & \multirow{2}{*}{$\begin{array}{l}\text { Response } \\
\text { uncertainty }\end{array}$} & KLR1 & 0.913 & 0.361 & Valid \\
\hline & & KLR2 & 0.867 & 0.361 & Valid \\
\hline \multirow{9}{*}{$\begin{array}{l}\text { Strategic } \\
\text { Flexibility }\end{array}$} & \multirow{2}{*}{ Perhatian } & SFP1 & 0.933 & 0.361 & Valid \\
\hline & & SFP2 & 0.852 & 0.361 & Valid \\
\hline & \multirow{2}{*}{ Assesment } & SFA1 & 0.825 & 0.361 & Valid \\
\hline & & SFA2 & 0.876 & 0.361 & Valid \\
\hline & \multirow{2}{*}{ Tindakan } & SFT1 & 0.875 & 0.361 & Valid \\
\hline & & SFT2 & 0.893 & 0.361 & Valid \\
\hline & Profitability & KB1 & 0.850 & 0.361 & Valid \\
\hline & $\begin{array}{l}\text { Pertumbuhan } \\
\text { penjualan }\end{array}$ & KB2 & 0.704 & 0.361 & Valid \\
\hline & Efisiensi & KB3 & 0.845 & 0.361 & Valid \\
\hline
\end{tabular}

Sumber : Data primer diolah (2016)

Berdasarkan ringkasan hasil pengujian validitas instrumen penelitian diketahui bahwa semua nilai koefisien korelasi item dengan skor total $\left(\mathrm{r}_{\mathrm{iT}}\right)>$ nilai korelasi tabel $\left(\mathrm{r}_{\text {tabel }}\right)$. Dengan demikian item pertanyaan pada dimensi state uncertainty, effect uncertainty, response uncertainty, perhatian, assesment, tindakan, dan variabel kinerja bisnis dinyatakan valid atau mampu mengukur variabel tersebut, sehingga dapat dipergunakan sebagai alat pengumpul data dalam penelitian ini. Untuk pengujian reliabilitas instrumen dimaksudkan untuk mengetahui kehandalan dan konsistensi instrumen penelitian sebagai alat untuk mengukur variabel yang diukurnya. Pengujian reliabilitas menggunakan teknik Cronbach's Alpha. Kriteria pengujian menyatakan apabila koefisien Cronbach's Alpha $\geq 0.6$ berarti item kuesioner dinyatakan reliabel atau konsisten dalam mengukur variabel yang diukurnya (Malhotra, 2012: 317). Adapun ringkasan hasil pengujian reliabilitas sebagaimana pada tabel 2 
Tabel 2. Hasil Uji Reliabilitas Instrumen

\begin{tabular}{llccc}
\hline \multicolumn{1}{c}{ Variabel } & \multicolumn{1}{c}{ Dimensi } & $\begin{array}{c}\text { Koefisien } \\
\text { Reliabilita } \\
\mathbf{s}\end{array}$ & $\begin{array}{c}\text { Cut } \\
\text { Off }\end{array}$ & $\begin{array}{c}\text { Keteranga } \\
\mathbf{n}\end{array}$ \\
\hline & $\begin{array}{l}\text { State } \\
\text { uncertainty }\end{array}$ & 0.841 & 0.6 & Reliabel \\
$\begin{array}{l}\text { Ketidakpastian } \\
\text { Lingkungan }\end{array}$ & $\begin{array}{l}\text { Effect } \\
\text { uncertainty }\end{array}$ & 0.859 & 0.6 & Reliabel \\
& $\begin{array}{l}\text { Response } \\
\text { uncertainty }\end{array}$ & 0.731 & 0.6 & Reliabel \\
\hline Strategic & Perhatian & 0.723 & 0.6 & Reliabel \\
Flexibility & Assesment & 0.616 & 0.6 & Reliabel \\
Kinerja Bisnis & Tindakan & 0.719 & 0.6 & Reliabel \\
\hline
\end{tabular}

Sumber : Data primer diolah (2016)

Berdasarkan ringkasan hasil pengujian reliabilitas instrumen penelitian diketahui bahwa semua nilai Cronbach's Alpha > 0.6. Dengan demikian item pertanyaan pada dimensi state uncertainty, effect uncertainty, response uncertainty, perhatian, assesment, tindakan, dan variabel kinerja bisnis dinyatakan reliabel atau konsisten dalam mengukur variabel tersebut, sehingga dapat dipergunakan sebagai alat pengumpul data dalam penelitian ini.

Berdasarkan diagram jalur pada penelitian ini maka dibutuhkannya Convergent Validity $1^{\text {st }}$ order yamg dimaksudkan untuk mengetahui valid tidaknya item dalam mengukur dimensi (Hair., et al, 1995). Convergent validity $1^{\text {st }}$ order setiap item dalam mengukur dimensi ditunjukkan oleh besar kecilnya loading factor. Suatu item dikatakan valid apabila loading factor bernilai positif dan lebih besar 0.5 . Hasil pengujian Convergent Validity $1^{\text {st }}$ order dapat dilihat melalui tabel 3

Tabel 3. Hasil Uji Convergent Validity $1^{\text {st }}$ order

\begin{tabular}{llccc}
\hline Variabel & Dimensi & Item & $\begin{array}{c}\text { Original } \\
\text { Sample (O) }\end{array}$ & $\begin{array}{c}\text { Keteran } \\
\text { gan }\end{array}$ \\
\hline & & KLS1 & 0.820 & Valid \\
& State & KLS2 & 0.717 & Valid \\
& KLS3 & 0.839 & Valid \\
Ketidakpastian & & KLS4 & 0.931 & Valid \\
Lingkungan & & KLS5 & 0.876 & Valid \\
& Effect & KLS6 & 0.816 & Valid \\
& uncertainty & KLE2 & 0.885 & Valid \\
& Response & KLR1 & 0.918 & Valid \\
& uncertainty & KLR2 & 0.935 & Valid \\
& & & & Valid \\
\hline
\end{tabular}

\begin{tabular}{lllcl}
\hline \multicolumn{1}{c}{ Variabel } & Dimensi & Item & $\begin{array}{c}\text { Original } \\
\text { Sample (O) }\end{array}$ & Keterangan \\
\hline \multirow{4}{*}{ Strategic } & Perhatian & SFP1 & 0.885 & Valid \\
Flexibility & SFP2 & 0.903 & Valid \\
& & SFA1 & 0.895 & Valid \\
& Tindakan & SFT1 & 0.913 & Valid \\
& SFT2 & 0.865 & Valid \\
& Profitability & KB1 & 0.858 & Valid \\
\hline \multirow{3}{*}{ Kinerja Bisnis } & Pertumbuhan & KB2 & 0.702 & Valid \\
& penjualan & & & Valid \\
& Efisiensi & KB3 & 0.791 & Valid \\
\hline
\end{tabular}

Sumber : Data primer diolah (2016)

Sedangkan model diagram jalurnya sbb:

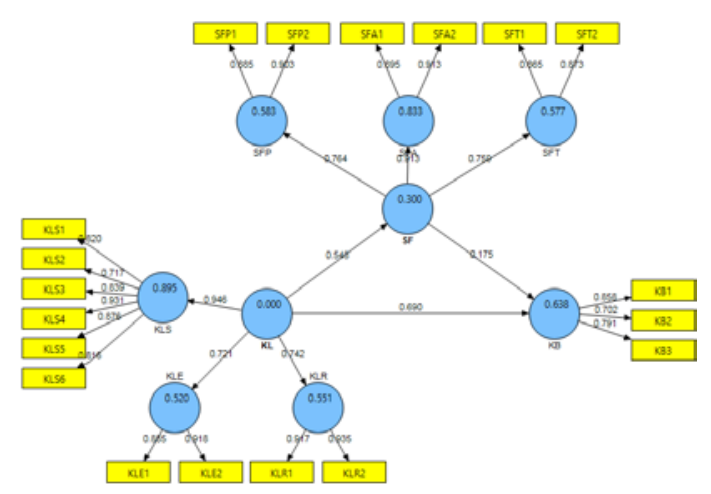

Gambar 1. Diagram Alur

Adapun untuk hasil Convergent Validity $2^{\text {nd }}$ order dimaksudkan untuk mengetahui valid tidaknya suatu dimensi dalam mengukur variabel laten (Haier., et al, 2010). Convergent validity $2^{\text {nd }}$ order setiap dimensi dalam mengukur variabel laten ditunjukkan oleh besar kecilnya loading factor. Suatu dimensi dikatakan valid apabila loading factor bernilai positif dan lebih besar dari 0.5.dapat dilihat dalam 4

Tabel 4. Hasil Uji Convergent Validity2 ${ }^{\text {nd }}$ order

\begin{tabular}{llcc}
\hline Variabel & Dimensi & $\begin{array}{c}\text { Original } \\
\text { Sample (O) }\end{array}$ & Keterangan \\
\hline \multirow{2}{\text{Ketidakpastian}}{$\begin{array}{l}\text { State uncertainty } \\
\text { Lingkungan }\end{array}$} & $\begin{array}{l}\text { Effect } \\
\text { uncertainty }\end{array}$ & 0.946 & Valid \\
& $\begin{array}{l}\text { Response } \\
\text { uncertainty }\end{array}$ & 0.742 & Valid \\
\hline Strategic & Perhatian & 0.764 & Valid \\
Flexibility & Assesment & 0.913 & Valid \\
& Tindakan & 0.759 & Valid \\
\hline
\end{tabular}

Sumber : Data primer diolah (2016) 
Pengujian reliabilitas yang dapat digunakan untuk menguji reliabilitas konstruk adalah cronbach alpha dan composite reliability. Kriteria pengujian menyatakan bahwa apabila composite reliability bernilai lebih besar dari 0.7 dan cronbach alpha bernilai lebih besar dari 0.6 maka konstruk tersebut dinyatakan reliable dapat dilihat melalui ringkasan yang disajikan dalam table 5 berikut:

Tabel 5. Hasil Uji Reliabilitas Konstruk

\begin{tabular}{lcc}
\hline Dimensi / Variabel & $\begin{array}{c}\text { Composite } \\
\text { Reliability }\end{array}$ & $\begin{array}{c}\text { Cronbachs } \\
\text { Alpha }\end{array}$ \\
\hline State Uncertainty & 0.932 & 0.912 \\
Effect Uncertainty & 0.897 & 0.771 \\
Response Uncertainty & 0.923 & 0.834 \\
Perhatian & 0.889 & 0.750 \\
Assesment & 0.899 & 0.777 \\
Tindakan & 0.860 & 0.676 \\
Kinerja Bisnis & 0.828 & 0.686 \\
\hline
\end{tabular}

Sumber : Data primer diolah (2016)

Goodness of fit Model digunakan untuk mengetahui besarnya kemampuan variabel endogen untuk menjelaskan keragaman variabel eksogen, atau dengan kata lain untuk mengetahui besarnya kontribusi variabel eksogen terhadap variabel endogen. Goodness of fit Model dalam analisis PLS dilakukan dengan menggunakan $Q$-Square predictive relevance $\left(Q^{2}\right)$. Adapun hasil Goodness of fit Model yang telah diringkas dalam tabel 6

Tabel 6. Hasil Goodness of fit Model

\begin{tabular}{ll}
\hline \multicolumn{1}{c}{ Variabel } & $\boldsymbol{R}^{2}$ \\
\hline Strategic Flexibility & 0.300 \\
Kinerja Bisnis & 0.638 \\
$\mathrm{Q}^{2}=1-\left(1-\mathrm{R}_{1}{ }^{2}\right)\left(1-\mathrm{R}_{2}{ }^{2}\right) \rightarrow$ & \\
$\mathrm{Q}^{2}=1-(1-0.300)(1-0.638)=0.747$ & \\
\hline Sumber : Data primer diolah (2016) &
\end{tabular}

Hasil analisa menunjukkan R-square variabel strategic flexibility bernilai 0.300 atau $30.0 \%$. Hal ini dapat menunjukkan bahwa keragaman variabel strategic flexibility dijelaskan oleh variabel ketidakpastian lingkungan sebesar 30.0\%, atau dengan kata lain kontribusi variabel ketidakpastian lingkungan terhadap variabel strategic flexibility sebesar $30.0 \%$, sedangkan sisanya sebesar $70.0 \%$ merupakan kontribusi variabel lain yang tidak dibahas dalam penelitian ini.

Hasil pengujian hipotesisi menunjukkan :

$\mathrm{H}_{1}$ : Pengaruh ketidakpastian lingkungan terhadap kinerja bisnis menghasilkan koefisien jalur sebesar 0.690 dengan nilai $\mathrm{T}$ statistics sebesar 10.814 . Dengan demikian hipotesis 1 diterima.

$\mathrm{H}_{2}$ : Pengaruh ketidakpastian lingkungan terhadap strategic flexibility menghasilkan koefisien jalur sebesar 0.548 dengan nilai $\mathrm{T}$ statistics sebesar 5.221. Dengan demikian hipotesis 2 diterima.

$\mathrm{H}_{3}$ : Pengaruh strategic flexibility terhadap kinerja bisnis menghasilkan koefisien jalur sebesar 0.175 dengan nilai $\mathrm{T}$ statisticssebesar 2.539. Dengan demikian hipotesis 3 diterima.

$\mathrm{H}_{4}$ :(Strategic flexibility akan mampu memediasi hubungan antara ketidakpastian lingkungan dengan kinerja bisnis) sebagai indirect effect

Hasil analisis menginformasikan variabel yang memiliki total efek terbesar terhadap kinerja bisnis adalah ketidakpastian lingkungan dengan total efek sebesar 0.785. Dengan demikian ketidakpastian lingkungan memiliki pengaruh yang paling dominan terhadap kinerja bisnis.

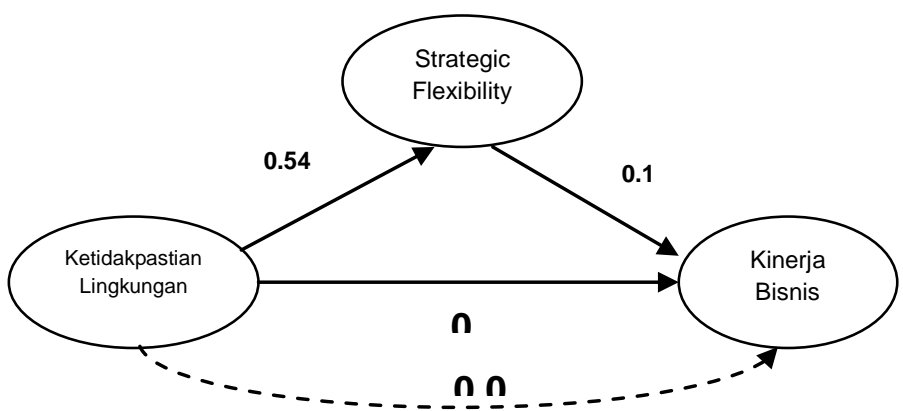

Untuk nilai VAF pengujian pengaruh variabel orientasi pasar terhadap loyalitas pelanggan memalui kepuasan pelanggan sebesar 0.122 atau $12.2 \%$. Nilai tersebut berada dibawah $20 \%$ sehingga dinyatakan bahwa variabel strategic flexibility tidak mampu memediasi secara parsial hubungan antara variabel ketidakpastian lingkungan terhadap kinerja bisnis 


\section{PEMBAHASAN}

Hasil penelitian menunjukkan bahwa terdapat pengaruh ketidakpastian lingkungan terhadap kinerja bisnis, ketidakpastian lingkungan terhadap strategic flexibility, strategic flexibility terhadap kinerja bisnis, dan strategic flexibility memediasi ketidakpastian lingkungan terhadap kinerja bisnis secara parsial. Secara keseluruhan hasil studi ini mengindikasikan bahwa bila ketidakpastian lingkungan sebagai kombinasi antara state uncertainty, effect uncertainty dan response uncertainty dapat dijadikan dasar oleh UKM developer dalam membentuk strategic flexibility, maka UKM Developer akan mampu memperbaiki atau meningkatkan kinerja bisnisnya

\section{Kesimpulan dan Saran}

Penelitian ini memberikan tambahan referensi hasil studi terkait persepsi managerowner terhadap ketidakpastian lingkungan, strategic flexibility, dan kinerja bisnis. Bagi pelaku bisnis strategic flexibility merupakan salah satu alat praktik manajemen untuk diterapkan dengan baik walaupun tanpa struktur organisasi yang mapan akan dapat menunjang keberhasilan kinerja bisnis tersebut. Oleh sebab itu penelitian di mendatang dapat mempertimbangkan untuk mengeskplor lebih jauh terkait fleksibilitas mengingat masih banyak golongan UKM yang belum menerapkan fleksibilitas.

Strategic flexibility dalam penelitian ini menjadi pemediasi persepsi manajerowner tentang ketidakpastian lingkungan terhadap kinerja bisnis. Hasil dari penelitian ini didapatkan bahwa strategic flexibility berpengaruh posistif dan signifikan khususnya pada dimensi assessment atau perhatian. Temuan ini menjadi dasar bagi pengembangan strategic flexibility untuk memperkaya penelitian yang menjadikan strategic flexibility sebagai pemediasi antara persepsi manager - owner tentang ketidakpastian lingkungan dan kinerja bisnis. Penelitian ini pula memberikan implikasi praktis yang diharapkan dapat memberikan pandangan bagi para pengambil keputusan. Berikut adalah hal-hal yang dapat dilakukan terkait dengan temuan penelitian ini. Penelitian ini memiliki implikasi praktis bahwa dalam usaha meningkatkan kinerja bisnis baik perlu adanya praktik strategic flexibility. Strategic flexibility merupakan ilmu manajemen terbaru yang seyogyanya dimiliki oleh mereka yang berkompeten dalam mengambil keputusan. Pentingnya peran strategic flexibility digambarkan oleh tiga dimensi utamanya yaitu perhatian, assessment, dan tindakan yang kesemuanya adalah bagian tak terpisahkan dalam mencapai goal perusahaan. Strategic flexibility merupakan kunci untuk tumbuh dan berkembang. Ketika perusahaan bercitacita ingin besar atau bersaing di pasar yang lebih luas maka kemampuan pada lini-lini manajerialnya harus diperkuat.

Pada hasil penelitian menyatakan bahwa perhatian pada peluang dan ancaman menghasilkan sikap manajer-owner secara berbeda. Secara keseluruhan mereka yang perhatian akan lebih mampu menilai atau melakukan assessment akan turbulensi lingkungan yang saat itu menimpanya. Sehingga pada akhirnya bermuara pada keberanian mengambil keputusan dan mengeksekusi strategi. Dimensi assessment memperoleh loading yang paling tinggi dibandingkan 2 dimensi yang lain. Developer disarankan untuk lebih berani melakukan assessment dibandingkan fokus pada tindakan yang sebetulnya assessment merupakan tindakan penting dalam mendukung peningkatan kinerja bisnis.

Terdapat pengaruh yang signifikan antara persepsi manager-owner tentang ketidakpastian lingkungan terhadap kinerja bisnis. Hal ini dapat ditunjukkan melalui peningkatan profit, pertumbuhan penjualan, dan efisiensi yang merupakan hasil langsung dari kemampuan manager-owner dalam memahami turbulensi lingkungan.

Terdapat pengaruh yang signifikan antara persepsi manager-owner tentang ketidakpatian lingkungan terhadap kecenderungan menerapkan strategic flexibility. Hal ini menunjukkan ketika manajer-owner turut memahami dan merasakan state uncertainty maka manager- 
owner akan bereaksi dalam menyikapi ketidakpastian tersebut dengan penerapan strategic flexibility sehingga menumbuhkan perhatian terhadap peluang dan ancaman, perhatian terhadap kelebihan dan kelemahan internal, memperhitungkan resiko dan berani mengubah strategi di saat strategi tersebut perlu untuk disesuaikan. Terdapat pengaruh yang signifikan antara persepsi managerowner tentang penerapan strategic flexibility terhadap kinerja bisnis. Hal ini menunjukkan ketika strategic flexibility sebagai keyakinan bagi manager-owner terhadap pengeksekusian strategi di masa depan yang menguntungkan maka peningkatan laba, pertumbuhan penjualan dan ekspansi proyek merupakan hasil langsung aktivitas penerapan strategic flexibility yang menanamkan komitmen untuk perhatian, assessment, dan kebranian dalam mengambil tindakan. Strategic flexibility memediasi persepsi manager-owner tentang ketidakpastian lingkungan terhadap kinerja bisnis. Hal ini menunjukkan bahwa strategic flexibility sebagai proses tidak langsung bagaimana ketidakpastian lingkungan mempengaruhi kinerja bisnis. Meskipun demikian peran mediasi strategic flexibility dalam menentukan besarnya pengaruh antara ketidakpastian lingkungan terhadap kinerja bisnis lebih kecil dibandingkan pengaruh langsung. Secara keseluruhan hasil studi ini mengindikasikan bahwa kombinasi antara ketidakpastian lingkungan dengan kompleksnya state uncertainty, effect uncertainty dan response uncertainty mendasari UKM Developer dalam membentuk strategic flexibility sehingga mampu memperbaiki atau meningkatkan kinerja bisnis. Berdasarkan hasil temuan penelitian bahwa dimensi assessment menghasilkan nilai loading paling tinggi dibandingkan dua dimensi yang lain namun rata-ratanya rendah. Artinya dimensi assessment belum bisa diterapkan dengan baik oleh manajer-owner, dengan demikian saran untuk developer dalam menghadapi state uncertainty tidak hanya fokus pada tindakan, namun harus diimbangi oleh assessment. Hal ini berarti kemampuan mengukur resiko wajib dimiliki oleh seorang manager-owner. Tindakan manajer-owner dalam menilai resiko, mempertimbangkan langkah-langkah strategik apa yang harus diambil merupakan kunci sukses dalam meningkatkan kinerja bisnis. Selain itu manager-owner juga disarankan untuk mulai belajar untuk menggunakan manajemen yang modern. Saran bagi para peneliti selanjutnya dapat mengembangkan model penelitian dengan: (1) menambahkan variabel lain seperti marketing flexibility, coordination flexibility, resource flexibility ; (2) memperluas cakupan penelitian ; (3) mengembangkan penelitian pada industri yang berbeda.

\section{DAFTAR PUSTAKA}

Arikunto, Suharsimi. 2004. Prosedur Penelitian: Pendekatan Praktis, Rineka Cipta, Bandung

Arnold, V., Benford, T., Canada, J., and Sutton, S. 2015. Leveraging integrated information systems to enhance strategic flexibility and performance: The enabling role of enterprise risk management. International Journal of Accounting Information Systems.Vol. $19: 1-16$.

Bastian, E. and Muchlish. M. 2012. Perceived Environment Uncertainty, Business Strategy, Performance Measurement Systems and Organizational Performance.Procedia Social and Behavioral Sciences.Vol65: $787-792$.

Bhimani, A. 2009. Risk management, corporate governance and management accounting: emerging interdependencies. Management Accounting Research Vol. 20: 2-5.

Boeker, W.B. (1989), "Strategic change: the effects of founding and history", Academy of Management Journal, Vol. 32 No. 3 : 489-516. 
Combe, I.A and Rudd, J.M. 2012.Antecedents to strategic flexibility management cognition, firm resources and strategic options.European Journal of Marketing.Vol. 46 No. 10. pp: 13201339

Cronbach LJ (1971) Test validation.In RL Thorndike (Ed),Educational measurement ( $2^{\text {nd }}$ edn).American Council on Education, Washington, DC.

Darya, I.G. 2012.Pengaruh Ketidakpastian Lingkungan Dan Karakteristik Kewirausahaan Terhadap Kompetensi Usaha Dan Kinerja Usaha Mikro Kecil Di Kota Balikpapan.Jurnal Inovasi dan Kewirausahaan.Vol. 1 p:65-78

Dyne,V.L, Graham, J.W., and Dienesch, R.M., $1994 . \quad$ Organizational Citizenship Behavior: Construct Redefinition, Measurement, and Validation. Academic Management Journal. Vol 37 (4): 765-802.

Eisenhardt, K.M. 1989. Making fast strategic decisions in high velocity environment.Academy of Management Journal.Vol. 32 No. 3. pp: 543-76.

Ferdinand, Augusty ,(2006) Metode Penelitian Manajemen, Metode Penelitian untuk Penulisan Skripsi, Tesis, dan Disertasi Ilmu Manajemen, Edisi 2 Badan Penerbit Universitas Diponogoro, Semarang.

Fuller, Badden C. (2006). To conform or to perform: Mimetic behaviour, legitimacy-based groups and performance consequences. Journal of Management Studies, 7(43), 15591581.

Ghozali, I, dan Fuad, 2012, Structural Equation Modeling: Teori, Konsep dan Aplikasi dengan program LISREL
8.80, Universitas Diponegoro, Semarang.

Hair, F.; Anderson, R.; Tatham, R.; Black, W.; Multivariate Data Analysis With Readings; $\quad 4^{\text {th }} \quad$ Ed.,Prentice-Hall International : London, 1995.

Hamel, G.Doz, Y.L. \& Prahalad, C.K., 1989. Collaborate With Your Competitor and Win. Harvard Business Review, January-February: 133-139

Hatch, Jim and Jeffery Zweig. 2001. Strategic Flexibility: The key to growth. Ivey Business Journal.Vol. 65: 44-47

Herman, R. T, Manggala, M. P, Sutjiadi, A, Yusuf, A.M. 2008.Analisis strategic flexibilitydan penerapan standar Euro 2 terhadap pengembangan produk.Journal of Business Strategy and Execution Vol. 1 No.1 November: $55-74$.

Herri and Wafa, S.A. 2003.The Influence of Internal and External Factors to the Performancer of Indonesian Small and Medium Enterprises.

Ho, Paul. 2014. An Exploratory Study Of The Impact Of Organizational Environments On Property Development Firms. Journal of Financial Management of Property and Construction. Vol. 19 No. 3, pp. 226245.

Hopkins, W.E. and Shirley E.H. 1997. Strategic Planning-Financial Performance in Bank: A Causal Examination. Strategic Management Journal. Vol. 18 (8): 635-652.

Hunger, J.D. dan Wheelen, T.L. 2002.Strategic Management and Business Policy. Eight Edition, Pearson Education. New Jersey. 
Jack, S.L. (2005), “The role, use and activation of strong and weak network ties: a qualitative analysis”, Journal of Management Studies, Vol. 42, pp. 1233-1259. JOCM 272-294.

Jogiyanto, H.M., 2014, Konsep \& Aplikasi PLS (Partial Least Square) untuk Penelitian Empiris, ANDI, Yogyakarta.

Kachra, Ariff and White, Roderick. 2008. Know-how transfer: The role of social, economic/competitive and firm boundary factors. Strategic Management Journal. Vol. 29 (4): 425445

Karim, Suhartini, 2007, “Analisis Pengaruh Kewirausahaan Korporasi terhadap Kinerja Perusahaan pada Pabrik Pengolahan Crumb Rubber di Palembang”, Jurnal Manajemen \& Bisnis Sriwijaya, Vol. 5, hal.42- 82.

Kasmir. 2008. Bank dan Lembaga Keuangan Lainnya. Edisi Revisi 2008. PT. Rajagrafindo Persada, Jakarta

Kock, N. (2010). Using WarpPLS in ecollaboration studies: An overview of five main analysis steps. International Journal of e-Collaboration, 6(4), 1-11.

Lau, T. Man, and Chow I. 2004. Organizational Capabilities and Performance of SMEs Dynamic and Stable Environments. Entrepreunership and Innovation. November: 354-371.

Li, Y., Liu, Y., Duan, Y., Li, M., 2008.Entrepreneurial orientation, strategic flexibilities and indigenous firm innovation in transitional China.International Journal of Technology Management.Vol: 41, 223246.

Li, Y, L., Su, Z. and Liu, Y. 2010. Fast adaption, strategic flexibility and entrepreneurial
Management Studies. Vol. 5 No. 3, pp. 256-271.

Liang, J., Li, L. and Song, F. 2013. An explanation of capital structure of China's listed property firms.Property Management. Vol. 32 No. 1, 2014 pp. 4-15

Luo, Y. 1999. Environment-StrategyPerformance Relations in Small Business in China: A Case of Township and Village Enter;prises in Southern China. Journal of Small Business Management. Jan 37 (1). ABI/INFORM Research: 103- 122.

Makhamreh, M. 2000. Corporate Performance in Jordan: A Study of the Banking Sector. Journal Review Vol. 2 (2).

Malhotra, K.N. 1999. Marketing Research An Appliend Orientation. Prentice-Hall International, Inc. New Jersey.

Milliken, F. J., 1987, Three Types of Perceived Uncertainty about Environment: State, Effect, and Response Uncertainty. Academy of Management Review 12: 133 - 143.

Nadkarni, S., Nareyanan, V.K., 2007. Strategic schemas, strategic flexibility, and firm performance: the moderating role of industry clockspeed. Strategic Management Journal 28, 243-270

Nazir, Salman., and Pinsonneault, Alain. 2012. IT and Firm Agility: An Electronic Integration Perspective. Journal of the Association for Information Systems. Vol. 13 : 150171.

Patel PC, Fiet JO. 2010. Enhancing the internal validity of entrepreneurial experiments by assessing treatment effects at multiple levels across multiple trials. Journal of Economic 
Behavior and Organization 76(1): Robert, N. and Stockport, J.G. 2009.Defining 127-140. StrategicFlexibility.Global Journal of Flexible Systems Management.Vol.10

Pearce, J.A. and Robinson, Jr. R.B. 2003.Strategic Management:

Formulation Implementation and Control. $8^{\text {th }}$ Edition Mc. Graw Hill International Edition. Malaysia.

Pearce, J.A., Robbin D.K. and Robinson, Jr. R.B. 1987. The Impact of Grand Strategy and Planning Formality on Financial Performance. Strategy Management Journal. Vol. 8: 124-134.

Perez, V.F, Morales, V.J,and Pulles, D.C. 2016. Entrepreneurial decision-making, external social networks and strategic flexibility: The role of CEOs' cognition. European Management Journal . Vol 34 : 296 - 309.

Probolinggo Times.(2015, 5 Oktober).Apersi Kebut Pembangunan 1 Juta Rumah. Diperoleh 21 Juni 2016, dari http://www.probolinggotimes.com/peris tiwa.htm

Purnama, Chamdan and Subroto W.P. 2016.Competition Intensity, Uncertainty Environmental on the use of Information Technology and its Impact on Business Performance Small and Medium Enterprises.International Review of Management and Marketing.Vol. 6(4): 984-992.

Purwanto, Arief. 2011. Ketidakpastian Lingkungan Bisnis Pengaruhnya dalam Budaya Organisasi.Jurnal Manajemen dan Akuntansi.Vol. 2, No. 2, Agustus 2013.

R. A. Supriyono, 1999, Manajemen Biaya : Suatu Reformasi Pengelolaan Bisnis, edisi pertama, cetakaan pertama, BPFE, Yogyakarta

Radar Bromo. 12 April, 2014. Evaluasi Kredit Bank Syariah Mandiri, hlm. 30.

Sugiyono, 1999. Metode Penelitian Bisnis. Jakarta. Alfabeta.

Rofiaty, (2012), Strategi Pengembangan UMKM Kerajinan Batik dan Jenang di Kabupaten Ponorogo Jawa Timur. Jurnal Aplikasi Manajemen FE Unibraw

Sanches, M. A., Vela-Jimenez, J.M., Perezperez, M., de-Luis-Carnicer, P. Interorganizational cooperation and environmental change: moderating effects between flexibility and innovation performance. British Journal of Management, in press.

Sekaran, Uma, 2003, Research for Methods for Bussiness, A Skill Building Approach, Fourth Edition, John Willey and Sons, Inc

Shane, S. and Kolvereid, L. 1995. National Environment, Strategy, and New Venture Performance: A Three Country Study. Journal of Small Business Management. Apr; 33 (2): 37-55.

Shimizu, K., and Hitt, M. A., 2004. Strategic flexibility: organizational preparedness to reverse ineffective strategic decisions. Academy of Management Executive. Vol. 18 No. 4

Sirmon, David. 2007. Managing resources in dynamic environments to create value : Looking inside the black box. Academy of Management Review.Vol 32 (1) : 273-292.

Soda, Giuseppe., Zaheer, Akbar., Carlone, Alessandra., 2008. Imitative behavior: Network antecedents and performance consequences. Advances in Strategic Management. Vol. 25:531-560 
Supriyanto, Eko. "Perbankan Syariah Mulai Jenuh”, Infobank Analisis - Strategi Perbankan \& Keuangan. 2016. P.7.

Sutrisno, 2001. Manajemen Keuangan Teori, Konsep dan Aplikasi, Edisi Pertama. Cetakan Kedua, Ekonisia,. Tunggal, A. Widjaja, 1995, Yogyakarta

SWA. 2016. Seperti Apa Tren Konsumen Properti Saat Ini. Website.

Tangen, Stefan. 2004. Performance Measurement: from Philosophy to Practice. International Journal of Productivity and Performance Management.Vol. 53 No. 8.

Thomas, B., Deshmukh, U.M., and Kumar, K.P. (2008).High Performing Organizations. New Delhi: McGraw Hill.

Timilsina, Binod. 2016. Does competitively distinct operation enable Performance in turbulent business environment? A study on finish SMEs.Management and Production Engineering Review.Vol. 7 No.3: 94-104.

Tushman, M.L. and O’Reilly, C.A. III. 1996. Ambidextrous organizations: managing evolutionary and revolutionary change. California Management Review. Vol. 38 No. 4, pp. 8-30.

UU No. 3/2014 Perumahan Rakyat

UU No. 21/2008 tentang Perbankan Syariah

Ward, P.T., Rebecca, D.G., Leong, K., dan Sum, C.C. $1995 . \quad$ Business Environment, Operation Strategy, and Performance: An Empirical Study of Singapore Manufactures. Journal of Operation Management, (13): 99-109.

Webb, J. and Dawson, P. (1991), "Measure for measure: strategic change in an electronics instruments corporation”, Journal of Management Studies, Vol. 28 No. 2, pp. 191-206.

Wikipedia. 2016. Kabupaten dan Kota Probolinggo. Diperoleh 28 Juli 2016, dari http://www.wikipedia.com

Wixom, B.H,; Watson, H.J. An Empirical Investigation of Factors Affecting Data Warehousing. MIS Quarterly 2001, 25(1), 17-41

Yang, J., Zhang, F., Jiang, X,.and Sun, W.,. 2015. Strategic flexibility, green management, and firm competitiveness in an emerging economy. Technological Forecasting \& Social Change. Vol 101: 347-356

Zahra, S.A., Hayton, J.C., Neubaum, D.O., Dibrell, C. and Craig, J. (2008), "Culture of family commitment and strategic flexibility: the moderating effect of stewardship”, Entrepreneurship Theory and Practice, Vol. 32, pp. 1035-1054.

Zhang, X., Shen, L., Wu, Y., Linda, C. 2009.Competitiveness Assessment for Real Estate Enterprises in China: A Model-Procedure. International Journal of Strategic Property Management. Vol. 13, 229-245

Zhang, X., Shen, L., Wu, Y., Peng, Y. 2010. Core Competitiveness Indicators: A Study of Real Estate Developers in China. Facilities. Vol. 28 No. 11/12, pp. 526-541

Zhang, X., Shen, L., Skitmore, M., Xia, B. 2010.Key Competitiveness Indicators for New Real Estate Developers.Journal of Financial Management of Property and Construction. Vol. 15 No. 2, pp. 143157 